\title{
PRKDC mutations associated with immunodeficiency, granuloma and aire-dependent autoimmunity
}

\author{
Alexandre Belot ${ }^{1,2^{*}}$, Anne-Laure Mathieu ${ }^{2}$, Estelle Veronese ${ }^{3}$, Gillian Rice ${ }^{4}$, Fanny Fouyssac ${ }^{5}$, Yves Bertrand ${ }^{6}$, \\ Capucine Picard ${ }^{7}$, Jolan Walter $^{8}$, Luigi Notarangelo ${ }^{9}$, Catharina Schuetz ${ }^{10}$, Heloise Reumaux ${ }^{11}$, \\ Mirjam Van Der Burg ${ }^{12}$, Helen Kemp ${ }^{13}$, Isabelle Rouvet ${ }^{14}$, Christophe Malcus ${ }^{15}$, Nicole Fabien ${ }^{16}$, Yanick Crow ${ }^{4}$, \\ Christine Menetrier-Caux ${ }^{3}$, Jean-Pierre De Villartay ${ }^{17}$, Thierry Walzer ${ }^{2}$
}

From 21st European Pediatric Rheumatology (PReS) Congress

Belgrade, Serbia. 17-21 September 2014

\section{Introduction}

PRKDC encodes for DNA-dependent protein kinase catalytic subunit (DNA-PKcs), a kinase that forms part of a complex (DNA-PK) crucial for DNA double-strand break (DSB) repair and V(D)J recombination. In mice, DNA-PK also interacts with the transcription factor AIRE (autoimmune regulator) to promote central $\mathrm{T}$ cell tolerance.

\section{Objectives}

We sought to understand the causes of an inflammatory disease with granuloma and autoimmunity, associated to decreasing $\mathrm{T}$ and $\mathrm{B}$ cell counts over time diagnosed in two unrelated patients.

\section{Methods}

Genetic, molecular, and functional analyses were performed to characterize an inflammatory disease evocative of a combined immunodeficiency.

\section{Results}

We identified $P R K D C$ mutations in both patients. These patients exhibited a defect in DNA DSB repair and V(D)J recombination. Circulating $T$ cells had a skewed cytokine response typical of Th1 and Th2 profiles. Moreover, mutated DNA-PKcs failed to promote AIRE-dependent transcription of peripheral tissue antigens in vitro. The latter defect correlated in vivo, with the production of antiCalcium Sensing Receptor (anti-CaSR) autoantibodies, which are usually found in AIRE-deficient patients.

'Pediatric Nephrology, Rheumatology and Dermatology, Hospices Civils de Lyon, France

Full list of author information is available at the end of the article

\section{Conclusion}

Deficiency of DNA-PKcs, a key AIRE partner, can present as an inflammatory disease with organ-specific autoantibodies and these findings highlight the essential role of DNA-PKcs in regulating autoimmune responses and maintaining AIRE-dependent tolerance in human.

\section{Disclosure of interest}

None declared.

\section{Authors' details}

'Pediatric Nephrology, Rheumatology and Dermatology, Hospices Civils de Lyon, France. 'U1111, INSERM, Lyon, France. ${ }^{3}$ U1052, INSERM, Lyon, France. ${ }^{4}$ Genetic Medicine, Manchester Academic Health Science Centre, University of Manchester, Manchester, UK. ${ }^{5}$ Hémato-oncologie pédiatrique Hôpital d'Enfants, CHU Nancy, Nancy, France. ' Institut d'hématologie et d'oncologie pédiatrique, Hospices Civils de Lyon, Lyon, France. ${ }^{7}$ Study Center for Primary Immunodeficiencies, IMAGINE, Necker, Paris, France. ${ }^{8}$ Division of Allergy/ Immunology, Harvard Medical School, Boston, USA. 'Division of Immunology, Boston Children's Hospital and Harvard Stem Cell Institute, Boston, USA. ${ }^{10}$ Department of Pediatrics and Adolescent Medicine, University Medical Center UIm, Ulm, Germany. ${ }^{11}$ Pediatric Rheumatology Unit, Jeanne de Flandre Hospital, Lille, France. ${ }^{12}$ Deptartment of Immunology, Erasmus MC, University Medical Center Rotterdam, Rotterdam, Netherlands.

${ }^{13}$ Department of Human Metabolism , The Medical School University of Sheffield, Sheffield, UK. ${ }^{14}$ Biotechnology, Hospices Civils de Lyon, Lyon,

France. ${ }^{15}$ Immunology Department, Hospices Civils de Lyon, Lyon, France.

${ }^{16}$ Immunology, Hospices Civils de Lyon, Lyon, France. ${ }^{17}$ U1163, INSERM, Paris, France.

Published: 17 September 2014

doi:10.1186/1546-0096-12-S1-P42

Cite this article as: Belot et al:: PRKDC mutations associated with immunodeficiency, granuloma and aire-dependent autoimmunity. Pediatric Rheumatology 2014 12(Suppl 1):P42.
Biomed Central

(c) 2014 Belot et al; licensee BioMed Central Ltd. This is an Open Access article distributed under the terms of the Creative Commons Attribution License (http://creativecommons.org/licenses/by/4.0), which permits unrestricted use, distribution, and reproduction in any medium, provided the original work is properly cited. The Creative Commons Public Domain Dedication waiver (http:// creativecommons.org/publicdomain/zero/1.0/) applies to the data made available in this article, unless otherwise stated. 